\title{
Screening Drug, Alcohol and Substance Abuse the Psychometric Measures
}

\author{
Mohamad Hashim Othman, Huzili Hussin, Kamarudin Hussin and N.S. Alias
}

\begin{abstract}
Urinalysis was used in previous studies among higher institution students $(\mathrm{n}=16252)$ in Malaysia to answer the question of whether university students are involved in drug abuse. However, the use of urinalysis had faced some problems. The problems were related to human rights issues and the cost to perform the urinalysis was expensive and quite impossible to be implemented to a large population of university students. To overcome this problem, this study was conducted to examine the effectiveness of psychometric measures in screening drug, alcohol and substance abuse. The Substance Abuse Subtle Screening Inventory A2 (SASSI-A2) was used for this purpose. SASSI-A2 is a brief screening tool designed to identify individuals who have a high probability of having a substance use disorder, including both substance abuse and substance dependence. SASSI-A2 comprises of 72 items that are rated on a two point scale with response; true and false. SASSI-A2 was translated into Malay language and it was refined through a back-translation technique and focus group approach. Psychometric testing was undertaken on a sample of 750 university students from five public universities in Malaysia. All participants were aged between 19 and 20 years. Internal consistency coefficients were calculated for the total scale and its subscales. Chronbach's alpha obtained for SASSI-A2 was 0.72 . This relatively high level of Chronbach's alpha showed relatively high level of reliability. The results demonstrated that the whole SASSI-A2 meets the fundamental measurement properties and can discriminate groups of higher institution students from high to low on the substance dependency variable. The accuracy of the test has been found to be unaffected by gender, ethnicity, age and years of education. Although more rigorous validation studies are needed, it is recommended that SASSI-A2 be considered for usage to higher institution students populations when a brief, objective, and accurate screening tool for chemical dependency is needed.
\end{abstract}

\section{Introduction}

Drug use and abuse remain as a critical problem in most countries and are often associated with several social and economic consequences. In recent years many adolescent including students in Higher Education Institutions (HEIs) engage in drug abuse. Since 2005, the Ministry of Higher Education (MOHE) has implemented a urinalysis for students of Higher Education Institutions (HEIs). A total of 16252 of students were involved in this study. Urinalysis were carried out to detect the involvement in drug abuse among HEIs students. In urinalysis conducted by Kamaruddin et al., (2013), $0.52 \%$ of respondents was 
detected involved in drug abuse. Despite its widespread use, urinalysis as a measure of unreported drug use is constrained by several limitations:

(i) Cost inefficient and it is impossible to administer to HEIs population.

(ii) Time consumption and requires expertise to conduct the urinalysis.

(iii) Human rights issue in collecting the urine specimens.

(iv) A narrow window of detection (36 to 72 hours), because many drugs are rapidly excreted (Baumgartner, [3]; Baumgartner, et al., [4]; Berka, 1991; Mieczkowski, et al., [15].

(v) Urine specimens require special handling and may pose a potential health risk to those collecting and assaying samples [15].

The above mentioned situations have created problems to conduct urinalysis in the future. Therefore, an alternative to the urinalysis should be identified. Substance use screening instruments can be helpful in determining if an individual has a problem with substance use, is at risk for developing one, or is in need of further assessment. Adger and Werner et. al [1] state that the goal of screening is to determine whether a problem exists and the "need for an in-depth assessment" (p. 124). Currently, a wide array of screening instruments is used to assess Substance Used Disorder (SUD) such as the Addiction Severity Index (ASI; McLellan, Luborsky, Woody, \& O'Brien, 1980; McLellan et al., [13], the Addiction Acknowledgement and Addiction Potential Scales (AAS; APS; Weed, Butcher, McKenna, \& Ben-Porath, 1992), the Drug Abuse Screening Test (DAST; Skinner, [18], and the Substance Abuse Subtle Screening Inventory (SASSI; Miller, 1985). SASSI is one of the most frequently used measures and more comprehensive instrument. It seems to be "especially effective in identifying early-stage chemically dependent individuals who are either in denial or are deliberately trying to conceal their chemical dependency pattern" [14]. Previous research has established that the SASSI-A2 has good psychometric properties $[6,19]$. Reliability coefficients are equally impressive and has a good level of validity to be used to identify users / abusers substance / drug of diverse backgrounds and gender [11]. Miller \& Lazowski (2001) reported that the percentage of accuracy with African American ethnicity was 90.2\%; Asian American 100\%; 94.5\% Caucasian; Hispanic American 93.8\%; 98.2\% Native American and other ethnic 93.5\%. Accuracy of measurement for men is $93.8 \%$ and $95.4 \%$ for females. Based on the scores obtained from SASSI-A2, respondents can be classified into four (4) categories that are; Low Probability (LP), Low Probability Frequently Abuse (LPFA), Substance Dependent Abuse (SDA) and Substance Dependent Disorder (SDD). The third (SAD) and fourth (SDD) categories are classified as at risk. The SASSI is an alcohol and drug screening measure and, therefore, was designed to distinguish individuals who may have an alcohol or drug use problem and expose the need for further assessment.

\section{Study objectives}

The aim of the present study was to examine the psychometric properties of a Malay version of the SASSI-A2 and the effectiveness of psychometric inventories to identify HEIs students involved in drug abuse. 


\section{Method}

For the purpose of this study, the researcher use a cross-sectional survey design and descriptive approach in a representative sample of 750 students from five Malaysian public HEIs. The respondents comprised of students who are at risk, such as; engaged in misconduct at the university, low achievement, health problems and other matters related to the university regulations.

\subsection{Instrumentation}

The psychometric properties of the Substance Abuse Subtle Screening Inventory-A2, an 72-item self-report questionnaire was evaluated. SASSI-A2 has also been translated in Japanese [9] Persian [20] and Spanish language [12, 16]. In this study the SASSI-A2 was independently translated from English into Malay by expert (Hambleton \& Jong, 2003). One of these expert were from Educational Psychology while the remaining two were bilingual expert. First, the researcher translated the items from the English language into Malay; secondly, the expert translated the items from Malay back into the English language. Finally, the researcher discussed the results and developed a common proposal and found that about $20.8 \%$ of the items conform to the original item, $8.3 \%$ need to revise while the remaining $70.9 \%$ correction should be made only on aspects of grammar and sentence structuring. Subsequently, the researchers also performed interrater reliability. Interrater reliability is the extent to which two or more individuals (coders or raters) agree. The number of experts selected was determined following the recommendations made by Crocker, Llabre, and Miller (1988) for obtaining useful estimates to adequately calculate interrater agreement. The recommendation is to select at least three interrater for each item (Lynn, 1986). Cohen's kappa (k) (Landis \& Koch, 1977) tests were used to determine the scores between the different raters. A pilot test was then conducted to determine the reliability of the instrument. A total of 152 samples were randomly selected from a public university to respond at SASSI-A2 instrument which has been refined. Analysis performed using a split-half reliability method. Results showed the coefficient obtained is 0.77 .

\subsection{Analysis}

Internal consistency was assessed using split half reliability. In the split-half reliability method, the SASSI-A2 was first divided into two equivalent halves and the correlation coefficient between scores of these half-test was found. In the present study the correlation coefficient was calculated by using Spearman formula and Brown formula. Meanwhile descriptive analysis was performing to determine the effectiveness of the SASSI in classifying respondents into four categories (LP, LPFA, SAD \& SDD).

\section{Results and Discussion}

Investigation into the reliability of the SASSI-A2 was conducted using the reliability tool under scale in the SPSS programme. Data was subjected to internal consistency reliability analyses; first, Cronbach's Alpha and second, split-half reliability. For the split-half reliability, both Spearman Brown Split-Half and Guttman Split-Half were obtained for the scale in general. The results of reliability test presented in Table 1 were obtained from the analysis conducted on the 72 items translated in Malay version of SASSI-A2.

Table 1: Reliability For SASSI-A2 


\begin{tabular}{|l|l|l|}
\hline No. of Items & 72 & $\mathrm{p}$ \\
\hline Cronbach's Alpha & .722 & $<0.05$ \\
\hline Spearman-Brown Coefficient & .729 & $<0.05$ \\
\hline Guttman Split-Half Coefficient & .728 & $<0.05$ \\
\hline
\end{tabular}

Effectiveness of the SASSI-A2

SASSI-A2 effectiveness in identifying respondents involved in drug abuse is based on four categories: LP, LPFA, SDA and SDD as can be seen in Table 2.

\begin{tabular}{|c|c|c|}
\hline SASSI-A2 & & Finding \\
\hline Low Probability (LP) & 371 & $49.5 \%$ \\
\hline $\begin{array}{l}\text { Low Probability } \\
\text { (LPFA) }\end{array}$ & 336 & $44.8 \%$ \\
\hline Substance Abuse Dependent (SAD) & 34 & $4.5 \%$ \\
\hline Substance Dependent Disorder (SDD) & 9 & $1.2 \%$ \\
\hline Total & 750 & $100 \%$ \\
\hline
\end{tabular}

\section{Discussion}

The aim of the present study was to examine the psychometric properties of a Malay version of the SASSI-A2 and the effectiveness of psychometric inventories to identify HEIs students involved in drug abuse. These findings indicate that drug screening can be done by using SASSI-A2. Undoubtedly urinalysis is more accurate, but this method can only be used on the small target group. In addition, urinalysis is not able to identify those who have the potential to be involved in drug abuse. The results of this study show that the SASSI-A2 can categorize respondents into four groups, namely LP, LPFA, SAD and SDD. This information allows the responsible party to plan ahead in order to curb drug abuse among groups that have been identified. This condition can help in providing interventions that focus on groups that have been identified through screening. The SASSI-A2 can also be conducted on the entire population of students of institutions of higher education in Malaysia through the online system. This system can save time, cost and analysis can be done immediately. The accuracy of the test has been found to be unaffected by gender, ethnicity, age and years of education. Although more rigorous validation studies are needed, it is recommended that SASSI-A2 be considered for usage to HEIs students populations. Based on the results of this study, SASSI-A2 has a high potential to be used as a screening test to identify HEIs students who abuse drugs.

\section{References}

1. Adger, H., \& Werner, M. J., The paediatrician. Alcohol Health and Research World, 18, 121-126, (1994)

2. Baer,J,D., Baumgartner, W.A., Hill, V.A., Blahd, W.H., Hair analysis for the detection of drug in pre-trial probation and parole populations. Fed Probat 55, 3$10,(1991)$ 
3. Baumgartner, W.A., Hill, V.A., Blahd, W.H., Hair analysis for drugs of abuse. Journal Forensic Science 34, 1433-1453, (1989)

4. Baumgartner, A.M., Jones, P.F., Baumgartner, W.A., Black, C.T., Radioimmunoassay of hair for determining opiate-abuse histories. Journal Nuclear Medicine 20, 748-52, (1979)

5. Berka C., New drug test offers significant advantages over traditional methods. Health Link, 4, 1-2, (1991)

6. Clements, R., Psychometric properties of the Substance Abuse Subtle Screening Inventory-3. Journal of Substance Abuse Treatment, 23(4), 419-423, (2002)

7. Cohen J., A coefficient of agreement for nominal scales. Educational Psychological Measurement, 20, 37-46, (1960)

8. DeVellis, R., Scale development: Theory and application. SAGE: Newbury Park, CA, (1991)

9. Kikuchi A, Wada K Nihon, The Japanese version of Substance Abuse Subtle Screening Inventory and its psychometric assessment. Arukoru Yakubutsu Igakkai Zasshi, 35(6), 388-401, (2000)

10. Landis, J.R., Koch, G.G., The measurement of observer agreement for categorical data. Biometrics, 33, 159-174, (1977)

11. Lazowski, L.E.; \& Miller, F.G., The adult substance abuse subtle screening inventory (3rd Ed.) manual. Springville, IL: The SASSI Institute, (1999)

12. Lazowski,L.E., Boye, M.W., Miller, G.A., \& Miller, F.G., The development and validation of the Spanish SASSI. Springville, IN: The SASSI Institute (2002)

13. McLellan, A. T., Luborsky, L., Woody, G. E. \& O'Brien, C. P., An improved diagnostic evaluation instrument for substance abuse patients: The Addiction Severity Index. Journal of Nervous and Mental Disease, 168, 26-33, (1980)

14. Merta, Rod J., Addictions counseling. Counseling and Human Development, 1-3

15. Mieczkowski, T., Landress, H.J., Newel, R., Coletti, S.D. (1993). Testing hair for illicit drug use. Washington, DC: National Institute of Justice, Document NCJ 137057, pp 1-5, (2001)

16. Miller, G. A., Supplement to the substance abuse subtle screening inventory manual. Bloomington, IN: Glenn A. Miller, (1994)

17. Polit, D.F., \& Beck, C.T., Nursing research: generating and assessing evidence for nursing practice. (8th. ed.) Philadelphia: Lippincott Williams \& Wilkins, (2008)

18. Skinner, H. A, The Drug Abuse Screening Test. Addictive Behaviors, 7, 363-371, (1982)

19. Swartz, J.A., Adapting and Using the Substance Abuse Subtle Screening Inventory-2 with Criminal Justice Offenders. Criminal Justice and Behaviour, 25(3), 344-365, (1998)

20. Vahid Sadeghi Firouzabadi, Reza Rostami, Nima Ghorbani, The reliability and validity of Substance Abuse Subtle Screening Inventory. Journal of Psychology, $13,206-224,(2009)$

21. Weed, N. C., Butcher, J. N., McKenna, T., \& Ben-Porath, Y. S., New measures for assessing alcohol and drug abuse with the MMPI-2: The APS and the AAS. Journal of Personality Assessment, 58, 389-404, (1992) 